\title{
Dynamic Amino Acid Side-Chains Grafting on Folded Peptide Backbone
}

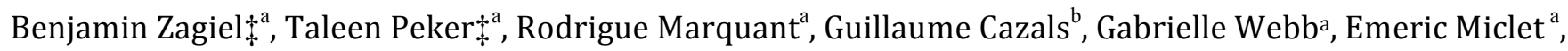
Claudia Bich ${ }^{b}$ Emmanuelle Sachonn, ${ }^{\mathrm{a}, \mathrm{c}}$ Roba Moumné*a

${ }^{a}$ Sorbonne Université, École normale supérieure, PSL University, CNRS, Laboratoire des biomolécules, LBM, 75005 Paris, France.

${ }^{\mathrm{b}}$ UMR 5247-CNRS-UM-ENSCM, Institut des Biomolécules Max Mousseron (IBMM), Université de Montpellier, Montpellier, France

${ }^{\mathrm{c}}$ MS33 platform, UFR 926, UFR 927, Sorbonne Université, 4 place Jussieu, 75005 Paris, France.

*roba.moumne@sorbonne-universite.fr

An efficient strategy for the synthesis of large libraries of conformationnally defined peptides is reported, using dynamic combinatorial chemistry as a tool to graft amino acid side chains on a well-ordered 3D peptide backbone. Combining rationnally designed scaffolds with combinatorial side chains selection represents an alternative method to access peptide libraries for structures that are not genetically encodable. This method would allow a breakthrough for the discovery of protein mimetic for unconventional targets for which little is known.

\section{Introduction}

Small peptides are attractive and underexploited compounds that occupy an intermediate molecular space between that of traditional drug-like compounds and much larger biologics. ${ }^{1}$ Their sizes allow them to occupy a large surface area on their binding partner leading to high affinity and selectivity, while maintaining pharmacokinetic properties that are much more favourable than biologics. Because their sequence can be directly derived from proteins, they incarnate the simplest functional protein mimetic. However, when removed from their native context, peptide segments usually fail to adopt the bioactive conformation, leading to entropic penalty upon binding that affects their affinity. Methods for pre-organizing peptide 3D structure have been developed over the last century, involving the use of constrained residues, head to tail or side-chain to side-chain macrocyclization, or projection of crucial side chains on 3D scaffolds. ${ }^{2}$ These methods allow the access to shorter Protein Domain Mimetic (PDM) that retain the activity of the whole protein and are particularly useful for targeting interactions that have revealed intractable with small molecules. $^{3}$ The limit of this rational design is that structural data on the protein to mimic have to be available. Additionally, they usually deliver a first low affinity hit, which is then optimized. This second task is usually performed by synthesis and screening of libraries of peptides and is often the most challenging and time-consuming step of the process. The other general approach for the discovery of bioactive compounds relies on high throughput screening of large libraries. Solid phase peptide synthesis as well as biological display technology allow to access encoded combinatorial libraries that can be easily identified after the screening. ${ }^{4}$ If these methods have been limited for long time to linear sequence with poor pharmaceutical properties, huge efforts have been devoted to their extrapolation to more "drug-like" sequences, endowed with peptidase resistance, cell permeability and oral bioavailability. Particularly, in vitro display system, such as mRNA and ribosome display allow the introduction of non natural amino acids and main chain features. ${ }^{5}$ We wish to develop an alternative strategy combining a rationally designed 3D peptide backbone and a combinatorial method to decorate this backbone with amino acid side chain functionalities. For this purpose, we propose to exploit Dynamic Combinatorial Chemistry (DCC) as a tool for side chains auto-assembly on the scaffold surface. ${ }^{6}$ The principle is outlined in Figure 1. 


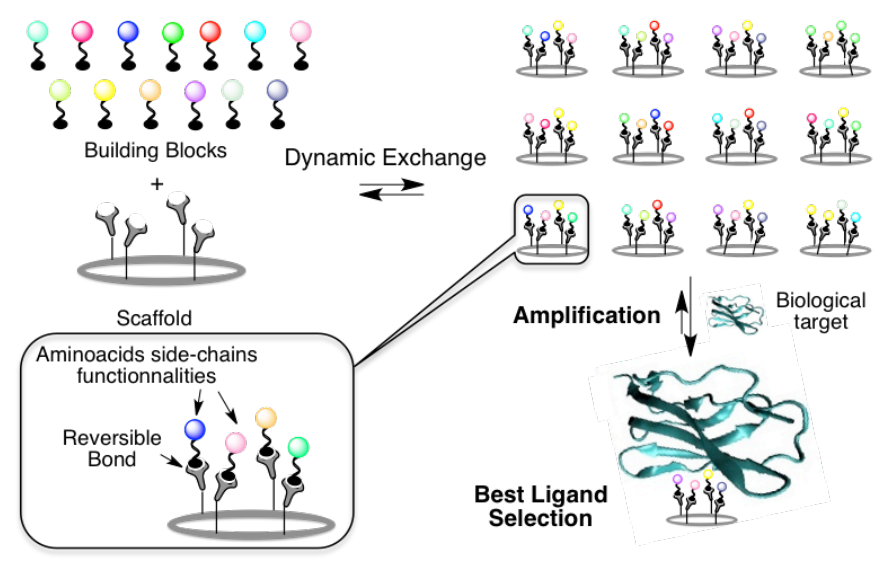

Figure 1. Protein mimetic design by dynamic side-chains grafting on a defined 3D peptide scaffold.

A peptide scaffold of defined 3D structure covered on one face by functional groups prone to react in reversible processes is mixed with a series of building blocks (BB) bearing amino acids side-chains, in physiological conditions. Dynamic side-chains grafting occurs and leads to a dynamic chemical library (DCL) of well-ordered peptides with multiple side chains combinations. Upon addition of a biological target, the best ligand binds this target and shifts the equilibrium to favour its own formation at the expense of the other compounds. Changes in library composition upon introduction of the target are thus exploited to probe favourable interactions. DCC has been barely used in peptide and peptidomimetic chemistry but few example are reported:7,8 to assemble peptides fragments into supramolecular 3D protein-like structure, ${ }^{9-11}$ to create peptide bonds between amino acids surrogates ${ }^{12,13}$ or to graft side chains either on a flexible polymer backbone ${ }^{14,15}$ or a rigid organic scaffold.16-18 The covalent reversible functionalization of a wellordered peptide scaffold has been also reported. ${ }^{19}$ Combination of such a folded scaffold with dynamic combinatorial method has never been published to date.

We present herein our incremental work aiming at generating a dynamic combinatorial library of 3D folded peptides. The key point for the success of this approach is to access an isoenergetic library, ensuring an equal quantity of all its members, since the formation of reaction mixtures that are strongly biased toward some of its members may render it energetically costly to shift the equilibrium in any other direction. Such phenomenon may strongly affect the level of amplification that could be detected and compromise its utility. We demonstrate here that an appropriate choice of reaction and conditions can lead to an effective thermodynamic control over the equilibrating mixture allowing the access to a library that would be useful for ligand screening and could achieve a breakthrough in the discovery of new bioactive peptides.

\section{Results and discussion}

First we focused on establishing conditions for the dynamic functionalization of a peptide scaffold, at its surface. Although many reversible reactions have been reported for DCC, only few of them are compatible with biological medium. ${ }^{6}$ For this purpose we chose the thioester exchange reaction, from a thiolfunctionalized scaffold and a library of thioester containing building blocks (BB), namely compounds $\mathbf{5}(\mathbf{X}), \mathrm{X}$ representing the different amino-acid side-chain carried by the BB (Scheme 1).15,20 This reversible reaction operates smoothly in water at neutral $\mathrm{pH}$ and low temperature. It is tolerant to the weak interactions involved in biomolecular recognition processes and even though thiol groups are part of protein composition, free cysteines are rare at protein surfaces and most often buried inside protein core where they stabilize the overall protein folding through disulfide bridging. We decided to use a scaffold bearing 4 
cysteines at its surface, since a minimum of 3-4 amino acid side-chains are usually involved in the pharmacophore of a protein.

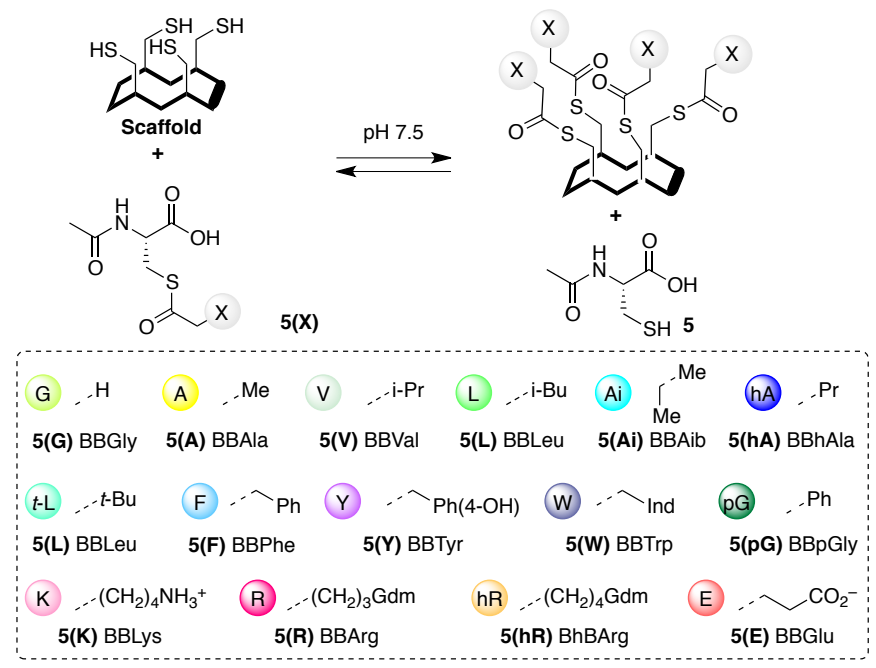

Scheme 1. Trans-thioesterification for side chain exchange between a peptide scaffold and amino acid side chains of different BB 5(X).

To establish the proof of concept, we selected a 10-mer cyclic peptide backbone containing a DPro-LPro $\beta$ turn inducing template, and a glycine residue at the opposite tip, known to fold into a regular and highly stable $\beta$-hairpin conformation. ${ }^{21,22}$ (Chart 1)

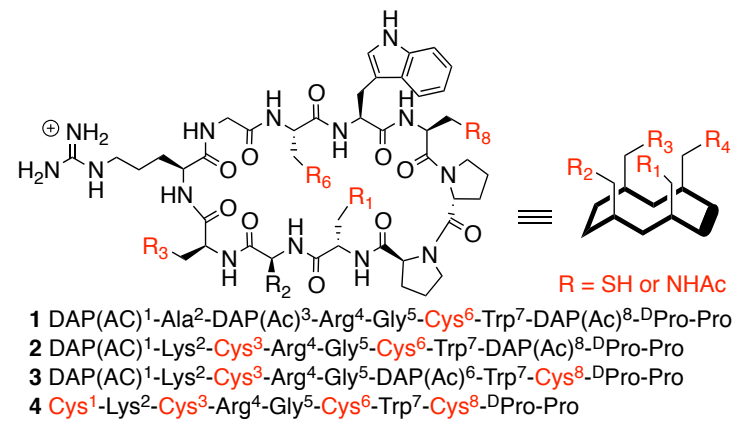

Chart 1. Scaffolds based on 10mer DPro-LPro templated $\beta$-hairpin cyclic peptides bearing 1,2 or 4 SH groups. DAP(Ac)= (3-acetyl)-1,3-Diaminopropionic acid

One face of the $\beta$-hairpin is covered with cysteine residues for reversible acyl exchange. Two positions on the opposite face and one in the loop are used to tune the properties of the peptide: cationic residues (Lys, Arg in position 2 and 4 respectively) ensure water-solubility and a UV tag (Trp in position 7) allows monitoring of the reaction at a specific wavelength $(280 \mathrm{~nm})$. Based on these design considerations, a series of peptides was prepared, bearing one (1), two (2 and 3) or four thiol groups (4) on one face, the other residues of the same face being locked as non-exchangeable acetyl-amide (NHAc). Peptide sequences are assembled by Solid Phase Peptide Synthesis (SPPS) using Fmoc/t-Bu strategy. ${ }^{23}$ In order to verify that these peptides adopt the expected conformation, the solution structure of $\mathbf{4}$ was investigated by NMR spectroscopy in aqueous solution at $300 \mathrm{~K}$ (phosphate buffer $\mathrm{pH} 7, \mathrm{H}_{2} \mathrm{O} / \mathrm{D}_{2} \mathrm{O}$ 9:1, tris-carboxyethylphosphine (TCEP) $10 \mathrm{mM}$ ). Proton and carbon assignments were unambiguously achieved using ${ }^{1} \mathrm{H},{ }^{13} \mathrm{C}$, TOCSY, ROESY and ${ }^{1} \mathrm{H}-{ }^{13} \mathrm{C}$ HSQC experiments. 
The obtained spectra revealed a unique set of resonances suggesting the presence of a single conformation on the NMR timescale. NH resonances displayed a large spectral dispersion and high values were measured for most of the $3 J_{\mathrm{HN}-\mathrm{H}_{\alpha}}$ couplings ( $>9 \mathrm{~Hz}$ ) which was indicative of a stable extended conformation. In addition, numerous cross-hairpin connectivities typical from a regular $\beta$-hairpin were observed in the ROESY experiment. In particular strong sequential $d_{a, \mathrm{~N}}(i, i+1)$ ROEs were observed as well as cross-strand ROEs connectivities between the $\mathrm{NH}$ protons of $\mathrm{Cys}^{1} / \mathrm{Cys}^{8}$ and $\mathrm{Cys}^{3} / \mathrm{Cys}^{6}$, and the $\mathrm{C} \alpha-\mathrm{H}$ protons of Lys ${ }^{2} / \operatorname{Trp}^{7}$. The absolute values of amide proton temperature coefficients were very low for residues Cys ${ }^{1}$ and Cys $^{6}(0.9$ and $1.0 \mathrm{ppb} / \mathrm{K}$ respectively). The $\mathrm{H} / \mathrm{D}$ exchange rates for $\mathrm{NH}$ protons of these two residues were very slow compared to the other residues which is consistent with their involvement in intra-molecular H-bonding. All together, these data strongly support the presence of a regular $\beta$-hairpin conformation.

This series of peptides was thus validated to study the reversible side-chains exchange. In order to ensure similar reactivity between the scaffold and the BBs and guarantee an equilibrium between both, acyl sidechains that are dynamically exchanged during DCC experiments are also attached to a cysteine platform in the BB design, via a thioester linkage. (Scheme 1) Different BB $\mathbf{5}(\mathbf{X})$ that recapitulate the panel of natural and common non-natural amino acids side-chains have been synthesized according to the literature. 24

To facilitate the analysis of the reaction mixture, the reaction conditions were first established on peptide $\mathbf{1}$ bearing a single thiol group in position 6. Peptide $\mathbf{1}(1 \mathrm{mM})$ was incubated with a single thioester BB 5(F) (3, 5 or 15 equiv.) in a $100 \mathrm{mM}$ phosphate buffer, at pH 7 and room temperature. (Figure 2)

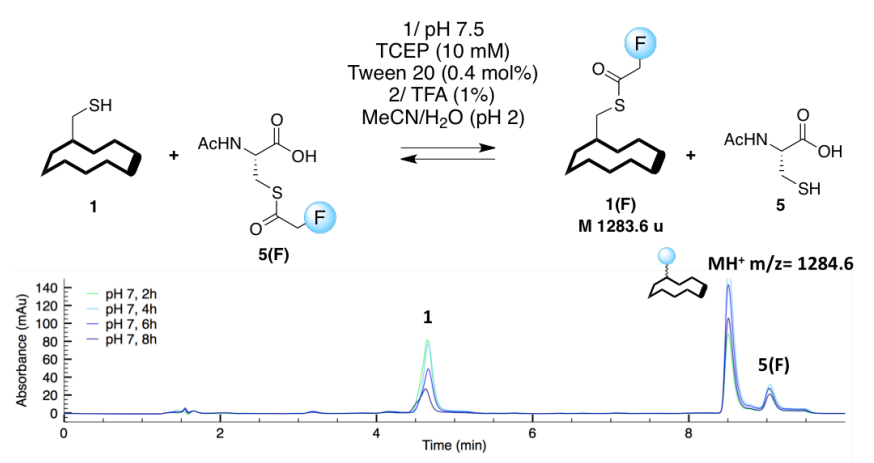

Figure 2. Thioester exchange between 1 and 5(F): reaction scheme (on the top) and RP-HPLC traces at $280 \mathrm{~nm}$ for the reaction followed over time (on the bottom)

The buffer contains TCEP (10 $\mathrm{mM})$ as reducing agent to avoid formation of by-products through disulfide bridging. Even though this competitive reaction is reversible at physiological $\mathrm{pH}$ and should not prevent the desired equilibrium, it could nevertheless complicate the analysis of the library content. Tween 20, a mild detergent compatible with biological medium, was used in a small amount $(0.4 \mathrm{~mol} \%)$ to prevent aggregation issues. After quenching the reaction through addition of TFA, formation of the acylated adduct 1(F) was followed by RP-HPLC at $280 \mathrm{~nm}$. The acyl anchoring reaction takes place smoothly leading to the expected thiol-acylated peptide as a sole new compound as confirmed by MS analysis $\left(\mathrm{MH}^{+}, \mathrm{m} / \mathrm{z}\right.$ 1284.6). Equilibrium between 1 and $\mathbf{1}(\mathbf{F})$ is established within $6 \mathrm{~h}$. The reaction can be slightly accelerated by raising the $\mathrm{pH}$ of the reaction mixture to 7.3 or 7.5 without modifying the reaction course. The $\mathrm{K}^{\prime}$ values were calculated from the steady-state concentration of each species, determined by RP-HPLC, and are in the range of 0.5-1. (Table 1) 
Table 1. Equilibrium constant $K^{\prime}$ for the transthioesterification of peptide 1 with a single BB 5(F) at different Scaffold to $\mathrm{BB}$ ratio and at different $\mathrm{pH}$.

\begin{tabular}{lllll}
$\mathrm{pH}$ & $\begin{array}{l}\text { Ratio } \\
\mathbf{1 : 5 ( F )}\end{array}$ & Time & $\begin{array}{l}\% \mathbf{1}(\mathbf{F}) \text { at } \\
\text { equilibrium }\end{array}$ & $\mathrm{K}^{\prime}$ \\
\hline 7 & $1: 3$ & $6 \mathrm{~h}$ & $66 \%$ & 0.6 \\
& $1: 5$ & $6 \mathrm{~h}$ & $73 \%$ & 0.5 \\
7.3 & $1: 15$ & $6 \mathrm{~h}$ & $92 \%$ & 0.7 \\
7.5 & $1: 5$ & $4 \mathrm{~h}$ & $82 \%$ & 0.6 \\
& $1: 10$ & $4 \mathrm{~h}$ & $87 \%$ & 0.6 \\
& $1: 1$ & $24 \mathrm{~h}$ & $50 \%$ & 0.7 \\
& $1: 4$ & $4 \mathrm{~h}$ & $80 \%$ & 1 \\
& $1: 5$ & $4 \mathrm{~h}$ & $87 \%$ & 1
\end{tabular}

The influence of the side-chain chemical nature on the reaction outcome was then studied. For this purpose, peptide $1(1 \mathrm{mM})$ was treated with different building blocks bearing the side chains of aliphatic, aromatic, polar, cationic or anionic amino acids, at different concentrations, in the conditions reported above. In all cases, a unique compound corresponding to the thioester adduct is formed as a sole new compound, as confirmed by MS analysis. ${ }^{23}$ (Table 2)

Table 2. Equilibrium constant $\mathrm{K}^{\prime}$ and analytical data for the transthioesterification product obtained from peptide $\mathbf{1}$ and different BB $\mathbf{5}(\mathbf{X})$.

\begin{tabular}{|c|c|c|c|c|c|}
\hline BB & Time & Product & $\begin{array}{l}\text { Molecular Formula } \\
(\mathrm{M}, \mathrm{Da})\end{array}$ & $\begin{array}{l}\mathrm{MH}^{+} \\
(\mathrm{m} / \mathrm{z})\end{array}$ & $\mathrm{K}^{\prime}$ \\
\hline $5(F)$ & $3 \mathrm{~h}$ & $1(F)$ & $\mathrm{C}_{59} \mathrm{H}_{81} \mathrm{~N}_{17} \mathrm{O}_{14} \mathrm{~S}(1283.6)$ & 1284.6 & $1.1 \pm 0.4$ \\
\hline $5(G)$ & $4 \mathrm{~h}$ & $1(G)$ & & 1194.6 & $0.8 \pm 0.4$ \\
\hline $5(A)$ & $3 \mathrm{~h}$ & & & & $5 \pm 0.1$ \\
\hline $5(\mathrm{~V}$ & $24 \mathrm{~h}$ & & & 1236.4 & $.2 \pm 0.1$ \\
\hline $5(t)$ & $24 \mathrm{~h}$ & & & 1250.6 & $\mathrm{NR}^{*}$ \\
\hline $5(1$ & $3 \mathrm{~h}$ & & & 1250.7 & $0.8 \pm 0.2$ \\
\hline & $24 \mathrm{~h}$ & & & 1222.6 & $0.7 \pm 0.1$ \\
\hline & $4 \mathrm{~h}$ & & & 1222.6 & $1.1 \pm 0.3$ \\
\hline $5(Y)$ & $4 \mathrm{~h}$ & $1(Y)$ & $\mathrm{C}_{59} \mathrm{H}_{8}$ & 1300.6 & $0.9 \pm 0.4$ \\
\hline $5(W)$ & $4 \mathrm{~h}$ & $1(W)$ & & 1323.6 & $0.8 \pm 0.4$ \\
\hline $5(p G)$ & $4 \mathrm{~h}$ & $1(p G)^{6}$ & $\mathrm{C}_{58} \mathrm{H}_{79} \mathrm{~N}_{17} \mathrm{O}_{14}$ & 1270.6 & $0.5 \pm 0.2$ \\
\hline $5(\mathrm{~K})$ & $4 \mathrm{~h}$ & $1(K)$ & $\mathrm{C}_{56} \mathrm{H}_{84} \mathrm{~N}_{18} \mathrm{O}_{14} \mathrm{~S}(1264.6)$ & 1265.6 & $0.6 \pm 0.4$ \\
\hline $5(R)$ & $6 \mathrm{~h}$ & $1(R)$ & $\mathrm{C}_{56} \mathrm{H}_{84} \mathrm{~N}_{18} \mathrm{O}_{14} \mathrm{~S}(1264.6)$ & 1265.6 & $0.9 \pm 0.1$ \\
\hline $5(h R)$ & $4 \mathrm{~h}$ & 1(hR) & $\mathrm{C}_{57} \mathrm{H}_{86} \mathrm{~N}_{20} \mathrm{O}_{14} \mathrm{~S}(1306.6)$ & 1307.8 & $1.3 \pm 0.5$ \\
\hline $5(E)$ & $4 \mathrm{~h}$ & 1(E) & $\mathrm{C}_{55} \mathrm{H}_{79} \mathrm{~N}_{17} \mathrm{O}_{16} \mathrm{~S}(1265.6)$ & 1266.6 & $0.4 \pm 0.3$ \\
\hline
\end{tabular}

Gratefully, no competitive reaction is observed when additional reactive functional groups are present on the side-chain. In general, the equilibrium is reached within few hours ( 3 to $6 \mathrm{~h}$ ) when an excess of BB is used ( $>1.5$ equiv.), but for $\beta$-branched side-chains (5(Ai) and $\mathbf{5 ( V )}$ ) additional time is needed. With $\mathbf{5}(\mathbf{t} \mathbf{L}$ ) bearing a $t$-butyl group, the equilibrium is not reached even after several days. In this case, the steric hindrance is too high and such BB can thus not be considered in this approach. The K' values obtained from all the other BBs are in the same range (0.4-1.3) meaning that the corresponding adducts are roughly isoenergetic. Even if slight differences exist, they are small enough to suggest that the dynamic library that would be generated from these different BBs should contain a close concentration of all the members which is, as discussed above, a key parameter for application of this reaction for screening. 
To prove the thermodynamic control over the reaction mixture, evolution of the library composition upon simultaneous (Exp 1) or sequential (Exp 2 \& 3) introduction and equilibration of three different BBs was achieved (Figure 3).

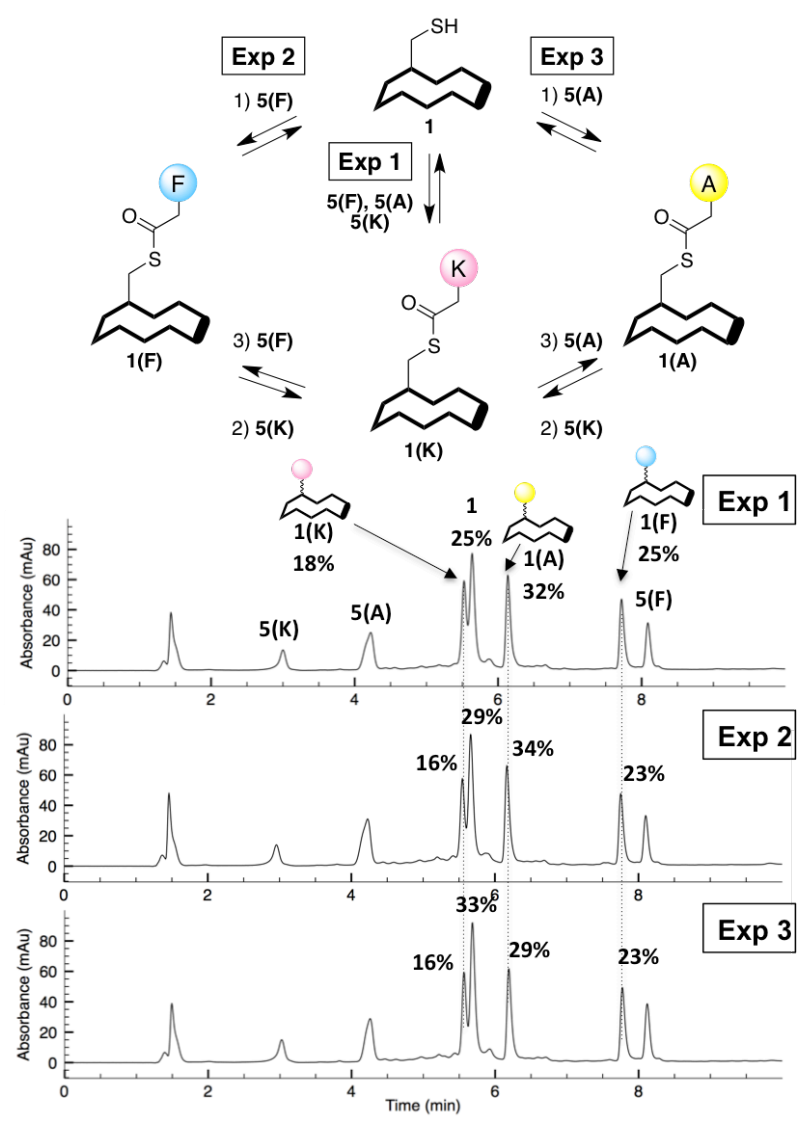

Figure 3. Study of the reversibility of the acyl exchange between $\mathbf{1}(1 \mathrm{mM})$ and $\mathbf{5 ( F ) , ~ 5 ( K )}$ and $\mathbf{5 ( A )}(=\operatorname{Exp} 1)$; $\mathbf{5 ( F )}$, then $\mathbf{5}(\mathbf{K})$ then $\mathbf{5}(\mathbf{A})(=\operatorname{Exp} 2) ; \mathbf{5}(\mathbf{A})$, then $\mathbf{5}(\mathbf{K})$ then $\mathbf{5}(\mathbf{F})(=$ Exp 3). Reaction scheme (on the top) and RP-HPLC traces at $280 \mathrm{~nm}$ (on the bottom)

In a first experiment (Exp 1) peptide 1 was treated simultaneously with 1 equiv. of $\mathbf{5 ( F ) , ~} \mathbf{5 ( K )}$ and $\mathbf{5 ( A )}$, leading at equilibrium (16h) to a mixture of $\mathbf{1}, \mathbf{1}(\mathbf{F}), \mathbf{1}(\mathbf{K})$ and $\mathbf{1}(\mathbf{A})$ in respectively $25,32,18$ and $25 \%$, as determined from the RP-HPLC peak areas. Two other series of experiments were performed in parallel, in which scaffold 1 (1 mM) was first reacted with 1 equiv. of either 5(F) (Exp 2) or 5(A) (Exp 3). After 16h, 1 equiv. of $\mathbf{5 ( K )}$ was introduced in each reaction mixture, and after 16 additional hours, the third BB, respectively 5(A) in Exp 2 and 5(F) in Exp 3 were added. Upon each addition step, the reaction mixture was analyzed by RP-HPLC and shows a reorganization of the library mixture, with the formation of a new adduct obtained from the added BB, at the expense of the adducts already present in the library. The amount of each adduct obtained in the different experiments are quite similar, unambiguously establishing the reversibility of the exchange.

Having established the little influence of the nature of amino acids side-chains functionalities on the thioester exchange reaction, the next step was to verify that the dynamic of the exchange is not modified by the proximity of another side-chain grafted on a nearby thiol group and to which extend interactions between side-chains on the scaffold surface can compromise the formation of a statistical library. To simplify the analysis and quantification of the library, peptides $\mathbf{2}$ and $\mathbf{3}$ containing two exchangeable sites in two different relative arrangements were used in these experiments. First, 2 or $3(1 \mathrm{mM})$ were reacted with a 
single BB, $\mathbf{5 ( A )}$ or $\mathbf{5 ( L )}$ at different ratios (4, 6 or 9 equiv.) in the conditions reported above. The reaction was followed by RP-HPLC overtime. (Figure 4A and B for 2, see SI for 3 )

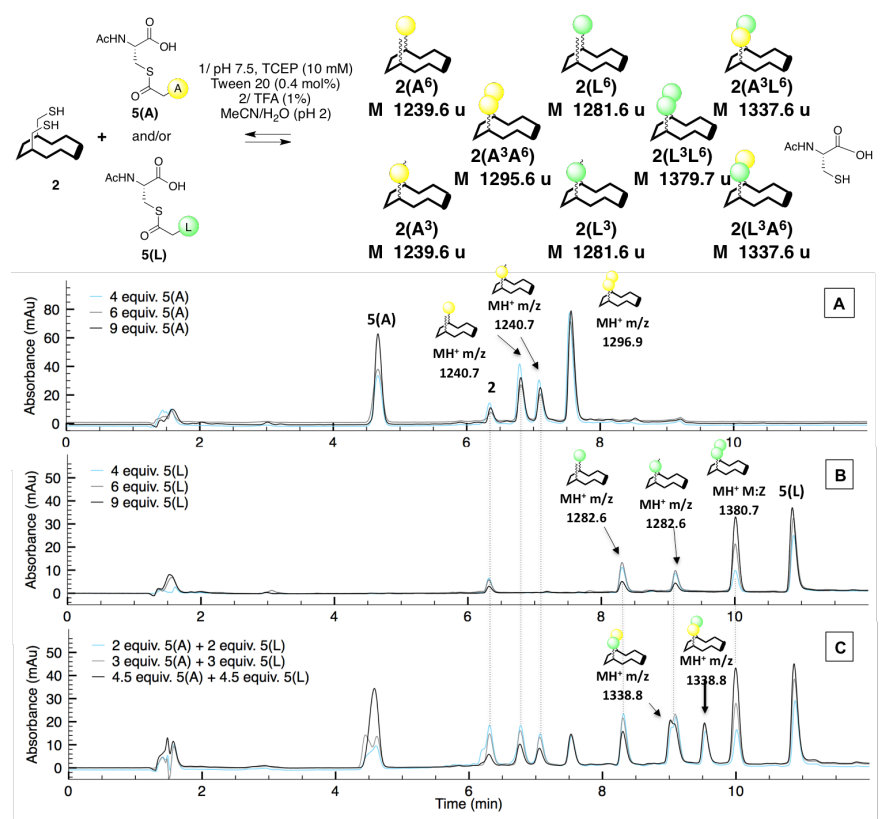

Figure 4. Reaction of $\mathbf{2}(1 \mathrm{mM})$ and $\mathbf{5 ( A )}$ or $\mathbf{5 ( L )}$ or both $\mathbf{5 ( A )}$ and $\mathbf{5 ( L )}$ (4, 6 or 9 equiv). reaction scheme (on the top) and RP-HPLC traces at $280 \mathrm{~nm}$ (on the bottom)

In both cases, the reaction leads in the first hour to two new HPLC signals in approximately equal amount, corresponding to the acylation of one of the two free cysteines, $\mathbf{2}\left(\mathrm{X}^{3}\right) / \mathbf{2}\left(\mathrm{X}^{\mathbf{6}}\right)$ or $\mathbf{3}\left(\mathrm{X}^{3}\right) / \mathbf{3}\left(\mathrm{X}^{\mathbf{8}}\right)$, respectively for 2 and 3 (the number in superscript indicates the position of the grafted side-chain). Then, the bis-acylated adducts $\mathbf{2}\left(\mathbf{X}^{3} \mathbf{X}^{6}\right)$ or $\mathbf{3}\left(\mathbf{X}^{3} \mathbf{X}^{8}\right)$ were formed, leading at equilibrium (around $12 \mathrm{~h}$ ) to the four compounds in different amount depending on the quantity of BB used in the reaction. Assignment of the sequences was achieved by MALDI MS. Identification of the isomeric peptides attached to the same acyl derivatives but in different positions can be obtained by MS/MS. For example, the two signals observed at 8.3 and $9.1 \mathrm{~min}$ in the RP-HPLC analysis of the mixture obtained from 2 and $\mathbf{5 ( L )}$, with the same $\mathrm{m} / \mathrm{z}$ value (1282.6), were submitted to MS/MS fragmentation and could be assigned to $\mathbf{2}\left(\mathbf{X}^{3}\right)$ at $8.3 \mathrm{~min}$ and $\mathbf{2}\left(\mathbf{X}^{6}\right)$ at $9.1 \mathrm{~min}^{23}$ The $\mathrm{K}^{\prime}$ values for each product was calculated according to its concentration at equilibrium. (Table 3) In both cases equilibrium constants for the acylation of each of the two thiol groups at $\mathrm{Cys}^{3}$ and $\mathrm{Cys}^{6}$ or $\mathrm{Cys}^{8}$ (respectively for $\mathbf{2}$ and 3) are very similar suggesting that the position of the thiol on the scaffold surface has no influence on its reactivity. Moreover, the equilibrium constant of the first and second acylation step, are in the same range, meaning that the presence of the first side chain does not prevent (or favour) the second grafting step. Concerning the nature of the anchored side chains, while the $\mathrm{K}^{\prime}$ values are nearly identical for $\mathbf{2}$, in the case of 3 the thiol/thioester equilibrium is slightly more shifted towards the acylated species when leucine side chain is used $\left(K^{\prime} \approx 3\right)$, compared to alanine $\left(K^{\prime} \approx 1\right)$, suggesting a stabilization of the grafted peptides in this case. This stabilization is probably due to favourable hydrophobic interactions between the hydrocarbon side-chain and the peptide backbone and/or side chains. However, the difference is small and should not compromise the observation of all adducts for libraries made of the two BBs. Indeed, when $\mathbf{2}$ or $\mathbf{3}$ are treated simultaneously with $\mathbf{5 ( A )}$ and $\mathbf{5 ( L )}(2,3$ and 4.5 equiv. of each) the eight expected peptides, including those bearing mixed $\mathrm{A}$ and $\mathrm{L}$ side-chains combinations are observed at equilibrium in quite similar amount. (Figure 4C for 2, see SI for 3) The variations observed in the $\mathrm{K}^{\prime}$ values may well be compensated by adjusting the concentrations of the BBs. 
Table 3. Equilibrium constant $K^{\prime}$ for the transthioesterification of scaffolds 2 and $\mathbf{3}$ with a single BB 5(A) or 5(L)

\begin{tabular}{llllll} 
Sca & BB & \multicolumn{3}{c}{ Equilibrium Constant K' } \\
& & $\begin{array}{l}\text { Acylation } \\
\text { Cys }\end{array}$ & & $\begin{array}{l}\text { at8 } \\
\text { Acylation at } \\
\text { Cys }^{3}\end{array}$ & $\begin{array}{l}\text { Acylation } \\
\text { Cys }^{3} \\
\text { Cys }^{\mathbf{6} / 8}\end{array}$ \\
\hline $\mathbf{2}$ & $\mathbf{5 ( A )}$ & $0.6 \pm 0.1$ & $0.5 \pm 0.1$ & $0.3 \pm 0.1$ \\
and \\
$\mathbf{3}$ & $\mathbf{5 ( L )}$ & $0.6 \pm 0.4$ & $0.5 \pm 0.2$ & $0.7 \pm 0.3$ \\
& $\mathbf{5 ( A )}$ & $1 \pm 0.5$ & $1 \pm 0.4$ & $0.6 \pm 0.1$ \\
& $\mathbf{5 ( L )}$ & $3.3 \pm 0.7$ & $3 \pm 0.7$ & $3.4 \pm 1$
\end{tabular}

Having proven on model systems containing one or two cysteine residues that the transthioesterification is an appropriate reaction to access isoenergetic libraries of peptides in terms of side chain nature, position and number, we finally moved to scaffold $\mathbf{4}$, bearing 4 cysteine groups on the same face. First, $\mathbf{4}$ was reacted with few representative BB individually, $\mathbf{5 ( G ) , 5 ( A ) , ~} \mathbf{5 ( L )}$ and $\mathbf{5 ( K )}$ leading as expected in each case to 15 new products at equilibrium (8h) bearing one, two, three or four grafted side chains on their surfaces. (Figure 5 shows the data obtained with $\mathbf{5 ( L )}$, for the other BB see SI)

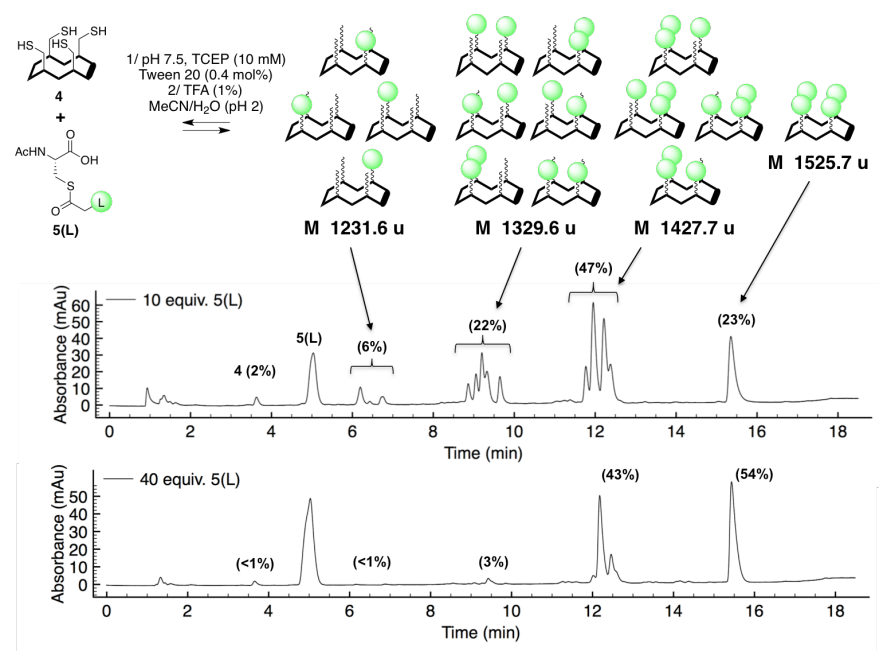

Figure 5. Reaction of $\mathbf{4}$ with 5(L): reaction scheme (on the top) and RP-HPLC traces at $280 \mathrm{~nm}$ (on the bottom), using 10 equiv. or 40 equiv. of $\mathbf{5 ( L )}$.

The amount of each compound depends mainly on the ratio of BB to scaffold used in the experiment as expected for a thermodynamically controlled process. Composition of the library can be thus tailored by controlling this ratio. The $\mathrm{K}^{\prime}$ values were calculated for each family of isomers bearing, one, two, three and four side chains. (Table 4)

Table 4. Equilibrium constant $K^{\prime}$ for the transthioesterification of 4 with a single BB 5(X).

\begin{tabular}{|c|c|c|c|c|c|}
\hline \multirow[t]{2}{*}{ BB } & \multirow[t]{2}{*}{$\mathbf{t}$} & \multicolumn{4}{|c|}{ Equilibrium Constant $K^{\prime}$} \\
\hline & & $\begin{array}{l}\text { Mono- } \\
\text { acylation }\end{array}$ & $\begin{array}{l}\text { di- } \\
\text { acylation }\end{array}$ & $\begin{array}{l}\text { Tri- } \\
\text { acylation }\end{array}$ & $\begin{array}{l}\text { Tetra- } \\
\text { acylation }\end{array}$ \\
\hline $5(G)$ & $4 \mathrm{~h}$ & $0.4 \pm 0.2$ & $0.6 \pm 0.1$ & $0.4 \pm 0.1$ & $0.2 \pm 0.1$ \\
\hline 5(A) & $16 \mathrm{~h}$ & $0.4 \pm 0.2$ & $0.8 \pm 0.2$ & $0.4 \pm 0.1$ & $0.2 \pm 0.1$ \\
\hline 5(L) & $9 \mathrm{~h}$ & $1.3 \pm 0.1$ & $1.2 \pm 0.2$ & $0.7 \pm 0.1$ & $0.2 \pm 0.1$ \\
\hline $5(\mathrm{~K})$ & $16 \mathrm{~h}$ & $1.6 \pm 0.5$ & $0.6 \pm 0.2$ & $0.2 \pm 0.1$ & $0.1 \pm 0.01$ \\
\hline
\end{tabular}


In general, the $\mathrm{K}^{\prime}$ for the three first acylation step are quite similar (for example $\mathrm{K}^{\prime} \approx 1$ for the mono- di and tri-acylated product with $\mathbf{5 ( L )}$ ), but a slightly smaller value is obtained for compounds decorated with 4 side chains $\left(\mathrm{K}^{\prime} \approx 0.2\right.$ with $\mathbf{5}(\mathbf{L})$ ). Here again the differences is quite small (one order of magnitude) and might be attributed to the steric hindrance obtained on the scaffold surface for the tetra-acylated compound. For cationic side-chain $(\mathbf{4}(\mathbf{K})$ ), electrostatic repulsion of the side chains on the scaffold surface adds to the steric effect. The multivalent assembly of a number of BB onto a single scaffold is in general disfavoured. However, the differences observed here are quite small and it has been shown on similar systems that the entropic cost associated to this process could be counterbalanced in the presence of a target in a DCC experiment and should not compromise the screening of such a library. ${ }^{19}$

Finally, the combinatorial aspect of the reaction was studied by mixing 4 with $\mathbf{5 ( L )}$ and $\mathbf{5 ( A )}$ simultaneously (20 equiv. of each) in the established conditions, leading theoretically to a library of 81 peptides. (Figure 6)

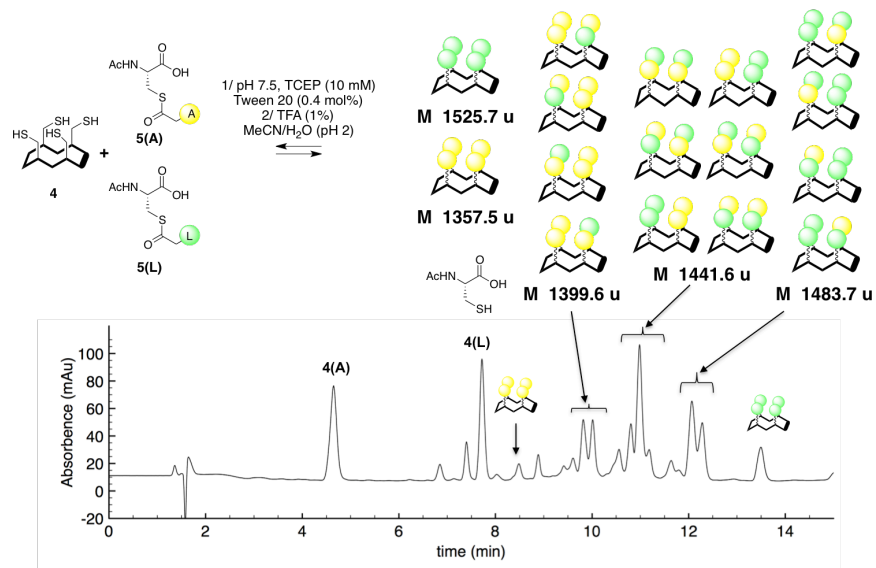

Figure 6. Reaction of $\mathbf{4}$ with $\mathbf{5}(\mathbf{L})$ and $\mathbf{5 ( A )}$ (20 equiv. of each BB): reaction scheme (on the top) and RP-HPLC traces at $280 \mathrm{~nm}$ (on the bottom). Only tetra-acylated adduct obtained as major compounds are indicated.

The equilibrium is reached after 8h. Isolation and MS analysis allowed identifying mono-, di-, tri- and tetraacylated compounds. Even if in this case we have not optimize the separation conditions in order to assign the analytical signal to different isomers, analysis of the reaction mixture shows that a wide variety of combinations is present at equilibrium with the peptide bearing three or four side-chains being obtained as major compounds as expected for a library made from large excess of BB. Identification of all analytical signals is a priori not mandatory to find new hits. For example, the largest DCL reported so far contains 9000 members and even though in such a library almost all compounds co-elute with many others, amplification by a template was observed and deconvolution allowed identification of the amplified compounds. ${ }^{25}$ Alternatively, isolation of the complex formed by the peptide and a biological target prior to analysis can be considered and allow to highly facilitate the DCC hit identification. ${ }^{26}$

In order to verify that the tethering of side chains on the scaffold surface does not affect the peptide 3D conformation, peptide $\mathbf{4}\left(\mathbf{G}^{\mathbf{1}} \mathbf{G}^{\mathbf{3}} \mathbf{G}^{\mathbf{6}} \mathbf{G}^{\mathbf{8}}\right)$ grafted with 4 glycine side chains was prepared on a larger scale and isolated. ${ }^{1} \mathrm{H}-\mathrm{NMR}$ spectra obtained for this peptide show similar spectral features to peptide $\mathbf{4}$, suggesting that side-chains anchoring does not disturb the peptide conformation. ${ }^{23}$

\section{Conclusions}

In conclusion, we have successfully designed an efficient, robust and original strategy to generate dynamic libraries of peptides with a well-defined 3D structure by combining a rationally designed 3D peptide scaffold 
with a dynamic combinatorial chemistry approach to graft amino acid side-chains on the peptide surface. A huge diversity of side-chains combinations could be obtained in this system depending on the number and nature of BBs used to generate the library. Dynamic libraries are in principle responsive to external changes and having demonstrated that the different thioester peptides obtained by the thioester exchange reaction are roughly isoenergetic, we can expect that these dynamic libraries represent a powerful screening tool for the rapid identification of peptide ligands. We are currently exploring its potential as a screening tool in different relevant biological contexts, and particularly in the challenging field of Protein-Protein Interaction inhibition.

\section{Author Contributions}

The manuscript was written through contributions of all authors. Project conceptualization and administration were achieved by R. Moumné. Investigations were conducted by B. Zagiel, T. Peker, R. Marquant and G. Webb for the synthesis part, E. Sachon, G. Cazals and C. Bich for the MS part and E. Miclet for NMR investigations. All authors have given approval to the final version of the manuscript.

\section{Conflicts of interest}

There are no conflicts to declare

\section{Notes and references}

(1) M. Muttenthaler, G. F. King, D. J. Adams, P. F. Alewood Nat. Rev. Drug Discov. 2021; 20(4), 309 ; Raines, R. T.; Wennemers, H. Acc. Chem. Res. 2017, 50, 2419.

(2) N. Sawyer, A. M. Watkins, P. S. Arora Acc. Chem. Res. 2017, 50, 1313

(3) E. Lenci, A. Trabocchi Chem. Soc. Rev. 2020, 49, 3262.

(4) C. Sohrabi, A. Foster, A. Tavassoli Nat. Rev. Chem. 2020, 4, 90.

(5) Y. Huang, M. M. Wiedmann, H. Suga Chem Rev. 2019, 119, 10360.

(6) P. Frei, R. Hevey, B. Ernst Chem. Eur. J. 2019, 25 (1), 60.

(7) J. W. Sadownik, R. V. Ulijn, Curr. Opin. Biotechnol. 2010, 21 (4), 401.

(8) Y. Liu, J.-M. Lehn, A. K. H. Hirsch Acc. Chem. Res. 2017, 50 (2), 376.

(9) J. F. Reuther, J. L. Dees, I. V. Kolesnichenko, E; T. Hernandez, D. V. Ukraintsev, R. Guduru, M. Whiteley, E. V. Anslyn, Nat. Chem. 2017, 10 (1), 45.

(10) E. Bartus, Z. Hegedüs, E. Wéber, B. Csipak, G. Szakonyi, T. A. Martinek ChemistryOpen 2017, 6 (2), 236.

(11) Z. Dadon, M. Samiappan, A. Shahar, R. Zarivach, G. A. Ashkenasy, Angew. Chem. Int. Ed. 2013, 52 (38), 9944.

(12) Y. M. Abul-Haija, R. V. Ulijn, Biomacromolecules 2015, 16 (11), 3473.

(13) Y. Ruff, V. Garavini, N. Giuseppone J. Am. Chem. Soc. 2014, 136 (17), 6333.

(14) C. S. Mahon, A. W. Jackson, B. S. Murray, D; A. Fulton Chem. Commun. 2011, 47 (25), 7209.

(15) Y. Ura, J. M. Beierle, L. J. Leman, L. E. Orgel, M. R. Ghadiri, Science 2009, 325 (5936), 73.

(16) A. Bugaut, K. Jantos, J.-L. Wietor, R. Rodriguez, J. K. M. Sanders, S. Balasubramanian Angew. Chem. Int. Ed. 2008, 47 (14), 2677.

(17) S. H. Hewitt, A; J. Wilson Eur. J. Org. Chem. 2018, 2018 (16), 1872.

(18) N. Busschaert, S. Thompson, A. D. Hamilton Chem Commun. 2017, 53, 313.

(19) E. Bartolami, Y. Bessin, V. Gervais, P. Dumy, S. Ulrich Angew. Chem. Int. Ed. 2015, 54 (35), 10183.

(20) B. F. Fisher, S. H. Hong, S. H. Gellman, S. H. J. Am. Chem. Soc. 2017, 139 (38), 13292 and references cited herein.

(21) J. A. Robinson Acc. Chem. Res. 2008, 41 (10), 1278.

(22) J. Robinson, L. T. Maillard, K. Möhle, R. Moumné, M. Seitz, D. Obrecht, H. Henze, A. Lederer, F. Gombert, 0. Sellier-Kessler W02010015287 A2, 2008.

(23) See Supporting Information

(24) A. R. Katritzky, S. R. Tala, N. E. Abo-Dya, K. Gyanda, B. E.-D. M. El-Gendy, Z. K. Abdel-Samii, P. J. Steel J. Org. Chem. 2009, 74 (18), 7165.

(25) R.F. Ludlow, S. Otto, S. J. Am. Chem. Soc. 2008, 130 (37), 12218. 
(26) For representative examples see: Z. Fang, W. He, X. Li, Z. Li, B. Chen, P. Ouyang, K. Guo Bioorg. Med. Chem. lett. 2013, 23(18), 5174; P. Frei, L. Pang, M. Silbermann, D. Eris, T. Muhlethaler, O. Schwardt, B. Ernst Chem Eur J. 2017; 23(48), 11570; L. Milanesi, C. A. Hunter, S. E. Sedelnikova, J. P. Waltho Chem. Eur. J. 2006, 12(4), 1081. 